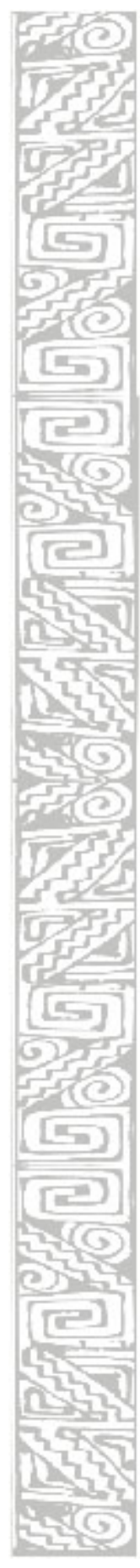

\title{
SUFRAMA: agência dos agentes
}

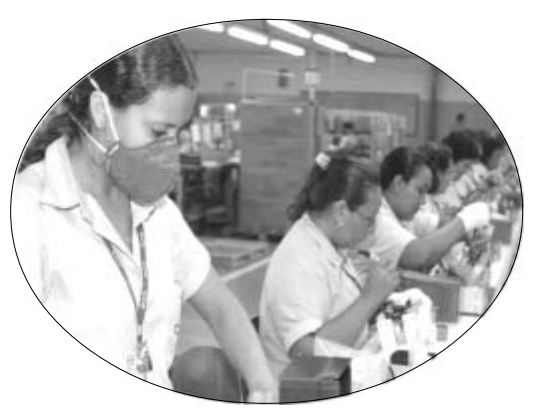

Izaura Rodrigues Nascimento ${ }^{1}$

Resumo

O texto aborda a Zona Franca de Manaus - ZFM em três momentos.

Primeiramente no contexto de sua implantação, no segundo momento a

SUFRAMA é caracterizada como agência de desenvolvimento e no terceiro momento são destacadas algumas questões que a perpassam na década de 90.

Palavras-chave

Desenvolvimento; industrialização; planejamento.

\section{Abstract}

In this text the Free Trade Zone of Manaus is approached in three moments. Firstly in the context of its installation, in the second moment SUFRAMA is characterized as development agency and in the third moment I look for to highlight some subjects that involve it in the decade of 90 .

Mestre em Ciências do Ambiente e Sustentabilidade na Amazônia pelo Centro de Ciências do Ambiente da Universidade Federal do Amazonas. Técnica do Instituto de Proteção Ambiental do Amazonas - IPAAM. Professora do Departamento de Ciências Sociais da Universidade Federal do Amazonas. 
Keywords

Development, industrialization, planning.

Na pesquisa que deu origem a este artigo, realizada no final da década de 90 , foram consultados livros sobre a temática, artigos e publicações de debates organizados pelo jornal $A$ Crítica. O critério de escolha desses materiais foi o debate sobre o desenvolvimento regional e a ZFM, realizados por políticos, intelectuais e técnicos da SUFRAMA. Foram utilizados também documentos do órgão, tais como as sete Atas disponíveis com seus respectivos anexos, bem como um texto sobre a história da SUFRAMA produzido pela Assessoria de Comunicação do órgão.

\section{O contexto de instalação da Zona Franca de Manaus}

A instalação da Zona Franca de Manaus ocorreu no contexto da "Nova Divisão Internacional do Trabalho". Esta nova divisão baseou-se na produção cada vez mais padronizada, voltada para o mercado mundial. Correspondendo, conforme aponta Freitas Pinto, a uma “nova estratégia do sistema capitalista mundial”, “...uma tendência a concentrar a influência de determinados países sobre determinadas regiões do mundo" (FREITAS PINTO, 1987, p. 29), concomitante a este movimento econômico do capitalismo, observamos o embate político entre as forças capitalista e socialista. A América Latina, desde o período pós-Segunda Guerra, como a maioria dos países sob o regime militar, busca o desenvolvimento nacional (SANDRONI, 1994, p. 95; MANTEGA, 1990, p. 12), aliada aos Estados Unidos, um típico representante da expansão capitalista.

As zonas francas possuem um modelo mundial definido pela ONUDI, dentre as exigências para sua instalação encontram-se: baixos salários, controle do Estado sobre os trabalhadores, além dessas, há, ainda, a orientação para a criação de um órgão administrativo central e autônomo, autorizado pelo governo e situado dentro da própria zona, para organizá-la e administrá-la (FREITAS PINTO, 1987, p. 26).

160 Somanlu, ano 4, n. 1, jan./jun. 2004 
No Brasil, a Zona Franca de Manaus, além de ser baseada neste modelo mundial é alicerçada na idéia de planejamento e esta está vinculada à idéia de Estado planejador, centralizador. Conforme nos ponta Simonsen, se inicialmente o planejamento "assumiu em realidade qualidade quase mística" no governo Kubitschek e tornou-se condição de respeitabilidade para João Goulart, foi no período militar que se impôs como método de racionalizar a ação governamental, a partir de um "programa macroeconômico" (SIMONSEN, 1974, p. 47).

Podemos destacar, a partir na própria fala dos planejadores, a segunda fase ou, talvez, a outra face do regime militar. A primeira caracteriza-se pela imposição, pela força, do controle social e político, já na segunda o controle impõe-se como racionalidade, implantando o que Marilena Chaui denomina como "a forma sutil de dominação” (CHAUÍ, 1982, p. 49; CANCLINI, 1983, p. 37), que embora não sendo no início, depois se torna elemento produtor de consenso. A administração racional de meio transformar-se-á em fim. Sua representação pretende-se "neutra", de aplicação da ciência representa-se como se ela fosse.

Um conjunto de medidas governamentais vai consolidando-se nos quadros regionais, com maior concentração na Regiões Norte e Nordeste, com as SUDENE, SUDAM, SUFRAMA.

O quadro regional do Norte e Nordeste: as intervenções mais significativas

Em Elegia para uma re(li)gião, Francisco de Oliveira revela-nos que o Nordeste, anterior à SUDENE, encontrava-se num estado problemático, de estagnação econômica, miséria. Diversas intervenções já haviam sido realizadas sem, contudo, alterar a situação daquela região; ao contrário, acabaram por tornar-se reféns, seja do Estado Oligárquico, caso do Departamento Nacional de Obras Contra as Secas DNOCS, seja da indústria paulista, caso do Instituto do Açúcar e do Álcool - IAA. Não que a SUDENE tenha alterado significativamente tal realidade, mas que aquele quadro propiciou uma série de expectativas quanto a uma ação governamental. 
Assim, diz-nos Oliveira, os rumos da SUDENE não estavam marcados "desde sempre e para sempre", e sim profundamente marcados pela "tragédia" da forma que tomaram as contradições do Nordeste, constituindo-se em ameaça à própria burguesia nacional, por um lado e pelas expectativas de um Francisco Julião, de um Miguel Arraes, do próprio Francisco de Oliveira, mas personagens do que indivíduos em si, porque sintetizam expectativas de classes sociais, de categorias e do próprio governo. Por isso é que na análise deste autor, caracterizar Miguel Arraes como populista, à época, seria reduzir as possibilidades de compreensão do processo social na sua dramaticidade; o populismo é a forma que as contradições tomam e não a ausência delas.

A peculiaridade da colonização portuguesa no Brasil e, particularmente na Amazônia, o luso-tropicalismo, já foi destacado por diversos autores, dentre os quais, Raimundo Faoro em relação ao Brasil, Silva e Souza em relação à Amazônia. A sociedade foi fundada com uma estrutura estamental, na qual a população nativa sofreu profunda degradação cultural. Segundo Márcio Souza, a superestrutura da ação portuguesa na Amazônia foi mais eficiente e impregnou-se de tal forma que gerou uma auto-imagem negativa e, concomitantemente, uma dominação patrimonialista.

O surgimento da elite política amazonense, por ele descrito, ocorre a partir do colono-chefe-militar, que vai se transformando num administrador sedentário: "[...] um estamento obediente aos interesses fiscais da Coroa e domesticado pela complicada malha jurídica e burocrática, mais ardilosa que o cipoal da floresta virgem" (SOUZA, 1990, p. 48). A independência do Brasil e seu tardio reconhecimento na Amazônia, em função da distância geográfica, não deixaram de revelar, segundo o autor, "o gosto oportunista da classe dominante, hegemonicamente portuguesa", tal foi a pressa de adequar-se à nova situação, o que seria corroborado com a Cabanagem.

O movimento, no qual se embatiam as Amazônias portuguesa, brasileira e indígena, embora revelasse profundas contradições internas, teve seu trágico desfecho com a elite, representando-se vitoriosa à custa do elemento nativo. Anos mais tarde, o poder central reconheceria essa representação oferecendo-lhe o estatuto de Província. Formava-se, assim, "a sociedade estamental baseada nos lances de boa vontade do poder central e na defesa de suas prerrogativas menores" (SOUZA, 1990, p. 51). 
Assim, na Região Norte, as tentativas de "integração nacional” têm início de forma dramática com a repressão à Cabanagem. A sociedade regional funda-se sobre os escombros dos sonhos cabanos, solapados pelo Brasil independente (SILVA, 1996). A elite amazônica, que se aliara às forças imperiais, passariam, a partir daí, a uma condição de subserviência, interrompida pelo surto de riqueza no período áureo da economia gomífera, quando, conforme assinala Márcio Souza, Manaus transformou-se numa caricatura da Europa (SOUZA, 1978, p. 98).

O autor acentua a diferença entre as elites do período colonial, do período mercantilista e do período imperialista (ciclo da borracha), mas reconhece a continuidade na superestrutura, nos costumes do estamento. Em 1900, Silvério Nery, restabelecendo o poder do estamento, agora no interior da estrutura republicana, inauguraria o caciquismo político no Amazonas. Nem a rebelião de 1924 pôde transformar o poder político no Estado do Amazonas.

$\mathrm{Na}$ ideologia da borracha, a região e o ouro-negro eram indissociáveis, o produto extrativo, dado a sua própria natureza, parecia inesgotável. A elite punha-se uma aura, independia do Estado Nacional.

No ciclo da borracha sucederam-se duas gerações: uma do naufrágio, conservadora, e a outra populista, voltada para as massas, representada por políticos, como Gilberto Mestrinho e Plínio Coelho, ao mesmo tempo a vida cultural ganha maior vigor com o Clube da Madrugada que, no entanto, não consegue mudar os rumos da política estadual, opõe muito mais o boêmio ao burguês.

A partir das circunstâncias internas assim como dos quadros nacional e internacional, temos uma série de políticas voltadas à ocupação e à retomada da economia extrativa e agrícola, com os planos de colonização, plano de valorização da borracha. A crise americana de matéria-prima, em decorrência da 2. ${ }^{a}$ Guerra Mundial, possibilitou uma retomada do extrativismo da borracha, porém com pouca duração.

Verificamos, assim, o quadro político e econômico que antecede a implantação da SUDAM e, por conseguinte, da SUFRAMA. As expectativas variavam em acordo com a proposta do deputado Francisco Pereira da Silva, que consistia na constituição de um porto de livre comércio, com as "reivindicações populares, 
sobretudo das classes empresariais e trabalhadoras", que em 1966 pressionaram um reexame da e com propostas como a do governo federal: Zona Franca, após a reformulação da primeira.

Poderíamos tomar como exemplo das expectativas as "esperanças" de Djalma Batista. A instalação da ZFM lhe parecia a aplicação da ciência ao desenvolvimento da Amazônia. Esta posição não pode ser tomada, no entanto, desprovida de sua análise crítica acerca da relação entre o desenvolvimento econômico e o desenvolvimento social, pois para Batista decifrar a "Esfinge", consistiria em analisá-la cientificamente, buscar compreender as suas peculiaridades regionais. A Zona Franca de Manaus seria a intervenção governamental, por seu alcance, mais eficaz no desencadeamento do desenvolvimento regional (Batista, 1976: 268).

Se tomarmos Márcio Souza, que publica seu livro $A$ expressão amazonense: do colonialismo ao neocolonialismo, na mesma época em que Djalma Batista publica $O$ complexo da Amazônia: análise do processo de desenvolvimento, veremos uma postura com menor entusiasmo. A ZFM aparece como o "neocolonialismo", no qual se teria realizado um golpe de estado na própria elite local, pois ocuparão os cargos subalternos, os diretivos ficando a cargo de pessoas de fora da região.

A SUFRAMA e as experiências das agências de desenvolvimento

As agências de desenvolvimento

Djalma Batista em O complexo da Amazônia: análise do processo de desenvolvimento faz uma avaliação das agências de desenvolvimento: o BASA, nas suas três fases (Banco da Borracha - 1942, Banco de Crédito da Amazônia - 1950 e, finalmente, Banco da Amazônia - 1966); a SPVEA - Superintendência do Plano de Valorização Econômica da Amazônia, e a SUDAM - Superintendência de Desenvolvimento da Amazônia. Sua leitura nos revela diversos aspectos que marcam a atuação dessas agências na região.

164 Somanlu, ano 4, n. 1, jan./jun. 2004 
O BASA, segundo Batista, pode ser considerado como o primeiro instrumento do processo desenvolvimentista. Sua primeira fase corresponde ao Banco da Borracha, criado para defender a borracha, porém a Amazônia acabou favorecendo e financiando o processo de transformação do produto nas áreas ricas do Brasil, particularmente as indústrias do Sul, além dos desvios de recursos para negócios imobiliários. Quando o banco passou a financiar todos os produtos, passou também a exigir o título de propriedade, o que os pequenos e os médios proprietários não possuíam, conseqüentemente a maior parte dos créditos passou às transações comerciais.

Na análise sobre o BASA, criado em 1966, Batista orienta-se pela questão: em que este banco estaria servindo a região como banco de desenvolvimento?, isto porque, analisando os relatórios do banco, de 1971, o autor depara-se com o montante de 47,5\% dos empréstimos concedidos aos Estados fora da região amazônica, como Piauí, Ceará, São Paulo, Rio Grande do Sul, inclusive ao Distrito Federal (BATISTA, 1976, p. 204). Aqui se revela novamente a dificuldade de apreender a função dessa agência de desenvolvimento regional quando quase 50\% dos empréstimos são concedidos a Estados de fora da Amazônia. Quanto a isso, afirma que entre os dados que não constam nos relatórios inclui-se a ausência de dados sobre as comissões pagas aos diretores do BASA, pelo movimento financeiro global, incluindo as liquidações.

Na conclusão sobre a ineficácia do BASA, o autor credita sua causa ao sistema extrativista ao qual estava engajado.

A Superintendência do Plano de Valorização Econômica da Amazônia SPVEA foi criada em janeiro de 1953 e instalada em junho do mesmo ano com o objetivo de incrementar o desenvolvimento da produção extrativa, agrícola, pecuária, mineral e industrial. Nas causas das dificuldades de sua estruturação estão, conforme Batista: a novidade de um organismo de desenvolvimento, a necessidade de disciplinar a aplicação das verbas, a inexistência de pessoal habilitado e a mentalidade de que tudo deveria provir do governo.

Entre as maiores contribuições da SPVEA para a região, encontram-se o levantamento das necessidades da região e o apoio à pesquisa histórica, ao INPA - 
Instituto Nacional de Pesquisas da Amazônia, a realização pioneira do primeiro curso de Planejamento Regional do Brasil em 1955. Vamos destacar aqui as dificuldades, por terem dados importantes para a análise da agência, sua estrutura interna. Temos: a "flutuação do cargo de superintendente, depois da primeira administração, ao sabor dos ventos políticos, sem levar em conta que cada escolhido tentava implantar uma nova orientação, sem que se fixasse a idéia de que o processo de valorização teria de ser a longo prazo. A heterogeneidade da Comissão de Planejamento era flagrante" (1976, p. 209), a criação de uma máquina burocrática emperrada, transformação da SPVEA num superestado, com poderes maiores que o dos governadores, em função dos recursos disponíveis, a hegemonia de técnicos estrangeiros.

Em 27 de outubro de 1966, a SPVEA transforma-se em SUDAM, cujo objetivo consistia em promover o desenvolvimento auto-sustentado da economia e o bem-estar social da região amazônica (BATISTA, 1976, p. 211). Os planos da SUDAM eram realizados por particulares, como Hidroservice, Serete e Planave. Na avaliação sobre a SUDAM, o autor destaca principalmente os investimentos em infra-estrutura.

As agências de desenvolvimento regional que antecederam a SUFRAMA apresentaram percalços, contradições. Poderíamos estabelecer uma relação de continuidade, uma tradição de constituição e/ou de configuração que tomam essas agências? O BASA, a SPVEA - Superintendência do Plano de Valorização Econômica da Amazônia, a SUDAM - Superintendência de Desenvolvimento da Amazônia apresentam distorções das suas finalidades. A ineficácia dessas agências, na análise de Djalma Batista, tem sua principal causa no subdesenvolvimento histórico-social e, por conseguinte, no subdesenvolvimento cultural, na medida em que não existem condições para aceitação de princípios racionais na promoção do desenvolvimento, bem como pessoas com formação científica que possam pensar racionalmente a região (1976, p. 208). Decorridos 30 anos de SUFRAMA, não podemos mais atribuir os problemas ao subdesenvolvimento cultural e poderíamos fazê-lo em relação às vicissitudes do capitalismo? É patente que apenas um destes aspectos é insuficiente para explicá-los, pois a ação decorre de uma série de combinações, e todas as tentativas conjugam-se em esforços para apreendê-las.

166 Somanlu, ano 4, n. 1, jan./jun. 2004 


\section{A SUFRAMA como agência de desenvolvimento}

A Zona Franca de Manaus foi criada pela Lei n. ${ }^{\circ} 3.173$, de 6 de junho de 1957, regulamentada em 1960 a partir de alterações do projeto do deputado Francisco Pereira da Silva, cuja proposta consistia em criar um porto franco com a finalidade de "constituir um entreposto de mercadorias estrangeiras para abastecimento dos países vizinhos, que fariam também, através dela, as suas exportações” (BATISTA, 1976, p. 259). De 1957 a 1967, a Zona Franca de Manaus correspondeu a uma área de livre comércio "similar aos demais portos livres do mundo", no próprio decreto é patente a inexistência de sua vinculação com o desenvolvimento econômico regional.

Em 28 de fevereiro de 1967, pelo Decreto-Lei n. ${ }^{\circ}$ 288, houve completa reformulação da Zona Franca, segundo Batista, visando promover o desenvolvimento do interior da Amazônia, dotando-a de bases concretas que viabilizassem o desenvolvimento da região: um centro comercial, um centro industrial e outro agropecuário (Zona Franca de Manaus: história e objetivos, 1996, p. 2). O discurso oficial, do planejamento, centraliza a justificação da criação da Zona Franca de Manaus em função das "desigualdades regionais".

A SUFRAMA - Superintendência da Zona Franca de Manaus, entidade autárquica, foi criada pelo Decreto n. ${ }^{\circ}$ 61.244, de 28 de agosto de 1967, com uma função bem definida de organizar e administrar a Zona Franca de Manaus, desde a criação de uma infra-estrutura apropriada à instalação das empresas à distribuição das cotas de importação.

Em fevereiro de 1976, Djalma Batista fazia um balanço sobre a criação da Zona Franca de Manaus. Os números sobre a receita tributária demonstravam a pujança do modelo, de 1968 a 1974 havia passado, em Manaus, de Cr\$ 1.749.678,00 para Cr\$17.881.784,78 e no Estado de Cr $\$ 32.580 .332,00$ para Cr\$ 211.019.113,00. Estes dados demonstravam claramente a mudança do centro de gravidade da economia do interior para Manaus, um aspecto positivo pela superação da economia extrativista e negativo em relação ao êxodo rural, com o abandono de culturas tradicionais.

Somanlu, ano 4, n. 1, jan./jun. $2004 \quad 167$ 
A Zona Franca de Manaus conta, atualmente (final da década de 90), com sete incentivos. A SUFRAMA administra quatro deles: Imposto de Importação, Imposto sobre Produtos Industrializados e o Imposto de Exportação e o quarto incentivo, que se refere à aquisição de lotes do Distrito Industrial ao preço de R\$ 1,00 o metro quadrado, com 10 anos de prazo para pagamento. Muitas empresas adquiriam os terrenos como incentivo e, posteriormente, revendiam-nos a preço de mercado, só recentemente houve adoção de novos critérios. O quinto e o sexto incentivos são administrados pela Superintendência do Desenvolvimento da Amazônia: consiste na isenção total ou parcial do Imposto de Renda e acesso ao Fundo de Investimento da Amazônia - FINAM. O sétimo incentivo é concedido na esfera do Estado do Amazonas: refere-se à restituição total ou parcial do Imposto sobre Circulação de Mercadorias e Serviços - ICMS.

\section{Os impactos sobre o "mundo amazônico"}

A ZFM adquiriu o caráter de um processo civilizatório na Manaus que perdera seu vigor no início do século, pois imprimiu uma nova dinâmica ao Estado, com os impactos culturais imediatos principalmente sobre a cidade de Manaus. Tais transformações partiram do que é mais exterior à cidade: as fachadas, as residências que se tornam lojas e vão se imbricando ao cotidiano, aos hábitos e "habitus". São diversas as percepções desse processo. As observações de Djalma Batista dão conta de que: "Desde que começou a funcionar em agosto de 1967, depois de reestruturada, a vida de Manaus se transformou radicalmente, abrindo-se uma avalanche de novas casas comerciais e iniciando-se uma atividade econômica trepidante, de há muito desaparecida da cidade, que se enchem de gente recém-chegada, à procura novamente dos outrora famosos filões de ouro", este processo passou a exigir e a forjar novos costumes conforme Ribeiro: "A fábrica é uma escola na qual os comportamentos, hábitos e atitudes adequados à produtividade são formados no próprio processo de trabalho" (1987, p. 275).

Com a implantação do Distrito Industrial, veio toda uma "reestruturação" urbana, prevista no próprio projeto da SUFRAMA, com inúmeros benefícios para 
os empresários, como a infra-estrutura para a instalação das indústrias, para o governo estadual, principalmente no que se refere ao montante do recolhimento do ICMS, que se converteu, por outro lado, em uma "desestruturação" urbana: a precariedade dos serviços prestados à população, a favelização mais intensa, a própria mudança na arquitetura. Diversos trabalhos da década de 80 demonstram a preocupação com o impacto da implantação da ZFM sobre a sociedade regional, em particular em Manaus e regiões adjacentes.

Nesses trabalhos, a ZFM não aparece como um projeto, mas como realidade que concorreu para o agravamento de diversos problemas sociais, tais como: moradia, saneamento, serviços de saúde, transporte. Assim, a migração, favelização, expropriação e a formação de proletários são analisadas como a outra face da instalação do pólo eletroeletrônico em Manaus. Se a oferta de empregos e o aumento da arrecadação foram conseqüências positivas para a região, por outro lado, quanto à condição social, houve um certo tipo de degradação, pois a massa urbana aí constituída torna-se objeto das medidas do capital e do Estado.

Se tomarmos o agravamento das condições urbanas na sua relação com a instalação da Zona Franca de Manaus, veremos um debate interessante entre João Pinheiro Salazar e Rosalvo Bentes. Para o segundo, o problema populacional, agravado desde a década de 70 (com o inchaço da cidade e os seus conseqüentes agravantes), ocorreu em função do declínio da economia gomífera e, por conseguinte, das atividades agrícolas que faziam parte daquele sistema, esta situação teria atuado como fator de expulsão do homem do interior. Salazar, que constrói sua tese num contraponto a Bentes, aponta outros elementos na análise do problema da moradia: a extinção da cidade flutuante e a Zona Franca de Manaus, que atuou como pólo de atração, além do que apresenta a defasagem entre o declínio da economia gomífera e o período no qual ocorre o inchamento da cidade. É interessante notar o aspecto econômico, em ambos, apontado como o fator mais relevante na migração.

Retomando a polêmica, Marlene Ribeiro demonstra que estes aspectos não são excludentes, mas partes de um único processo: o capitalismo no Amazonas com sua face expropriadora e construtora de uma massa operária. O que na década de 80 aparecia como debate, nos anos 90 aparece como algo inquestionável: "Esse fato reproduziu as condições clássicas do fenômeno, isto é, falta de condições de vida no 
campo, agindo como fator de expulsão e avanço industrial, e a concentração de empregos e a ampliação do mercado de bens e serviços na área urbana, agindo como fatores de atração, vinculados a uma ideologia do progresso associada ao urbano" (COSTA, 1993, p. 20). Nos trabalhos de Salazar e Marlene Ribeiro existem, ainda, a percepção da emergência de movimentos sociais: as invasões (como resistência às políticas habitacionais levadas a efeitos pelos governos, marcando uma nova atitude em face das arbitrariedades), a organização do Partido dos Trabalhadores e do Sindicato dos Metalúrgicos. Estes movimentos marcam as contradições entre capital e trabalho, entre Estado e sociedade civil, possíveis a partir de uma certa tomada de consciência, viabilizadas tanto pela densidade populacional e condições precárias de trabalho, quanto pela noção de direitos individuais, direito à propriedade privada, ou seja, pela própria inserção nas relações capitalistas.

A autora continua a supervalorizar o fator econômico sem levar em consideração os aspectos culturais e sua profunda influência nas migrações que ocorrem em todo o país. A cidade como símbolo de modernidade, "uma ideologia de progresso associada ao urbano", com isso não queremos negar a importância do econômico, mas tentar demonstrar que ele não está sozinho, nem exclusivamente acompanhado da ideologia enquanto distorção do real.

$\mathrm{Na}$ década de 90, os dados demonstram que o quadro mudou significativamente, mas não no sentido esperado. $\mathrm{O}$ impacto sobre a estrutura demográfica é inegável. A concentração populacional pode ser demonstrada conforme as informações do IBGE a partir dos levantamentos realizados em 1995 e 1996, segundo o qual o Amazonas possui 2.389.279 pessoas. Desse total, 1.157.357 vivem na capital e o restante nos demais 61 municípios do interior, ou seja, na capital está concentrada 48\% da população do Estado (A CRÍTICA, 11/1/98, E3). Os serviços urbanos também continuam concentrados na cidade de Manaus.

Observa-se assim que a Zona Franca de Manaus não promoveu o desenvolvimento regional, ou seja, não funcionou como pólo de irradiação do desenvolvimento econômico; ao contrário: parece ter retardado as possibilidades de desenvolver indústrias com matéria-prima regional pois "se, no âmbito estadual, a economia é marcada pela presença predominante do setor secundário na composição da renda (em virtude da participação do Distrito Industrial de Manaus),

170 Somanlu, ano 4, n. 1, jan./jun. 2004 
o mesmo não ocorre no interior, onde o setor primário constitui a principal fonte de renda e onde a industrialização da capital quase não induziu as melhorias tecnológicas, quer nas atividades agropecuárias, quer nas industriais" (COSTA, 1993, p. 25), quanto ao distrito agropecuário, até agora não se consegue vislumbrar os resultados.

\section{A SUFRAMA e sua direção}

A SUFRAMA como órgão administrativo acabou por constituir-se em um poder paralelo ao poder do governo estadual, pois está vinculado diretamente ao governo federal. Além de contar com um orçamento significativo, que para o ano de 1995 era em torno de US $\$ 100$ milhões, equivalentes ao orçamento da Prefeitura de Manaus (A CRÍTICA, 9/2/95, A12). Neste sentido é fundamental resgatarmos o artigo de Roberto Motta, com o título La Zone Franche de Manaus et le mode paria de la production, de sua pesquisa conclui que no interior deste aparelho burocrático o superintendente possui uma “aura imperial”. Nas palavras de Roberto Motta, é uma das posições mais importantes no serviço público brasileiro, é nomeado pelo presidente da República e possui uma importância concreta, equivalente ao governador eleito. É, concretamente, quem distribui as cotas de importação.

Este poder, ao mesmo tempo em que constitui uma aura, inviabiliza a sua manutenção, pois, conforme as observações de Motta, a mudança constante de superintendentes deve-se às dificuldades de alocar as cotas, quando são necessárias leituras conjunturais que passam pelas tendências ou as mudanças no mercado internacional, dos interesses ou orientações do governo federal, das possibilidades da Zona Franca e, acrescenta-se a esses elementos, a importância das relações entre os superintendentes e o governo do Estado do Amazonas. Além disso, os critérios oficiais para a distribuição das cotas não são muito claros, possibilitando diversas interpretações e gerando, assim, condições para a centralização das decisões e conferindo maior significado político ao cargo.

Algumas observações feitas por Clicério Vieira Nascimento Sá, atual superintendente da Coordenação de Estudos Econômicos e Empresariais - CEE, 
acerca dos superintendentes, evidenciam este fato: Rui Lins saiu por atritos com José Lindoso; Joaquim Igrejas Lopes se constituiu em uma medida apaziguadora; Delile Guerra de Macedo foi contemporizador do governo federal; Jadyr Magalhães assumiu sob a influência do governador Amazonino Mendes; Leopoldo Péres foi indicado pelo senador Bernardo Cabral; Alfredo Nascimento: indicado por influência do governador Amazonino Mendes; Manuel Rodrigues também sob a influência do governador Amazonino Mendes; Mauro Costa sob a influência do senador José Serra. Quanto à auto-imagem desta gestão, da qual faz parte, afirma que o superintendente Mauro Costa concebe a SUFRAMA como uma agência de promoção de investimento, e busca dar-lhe uma nova fisionomia.

As informações sobre as influências políticas na definição dos superintendentes da ZFM podem ser corroboradas pelo processo de sucessão do superintendente Manuel Rodrigues. Na lista de "suframáveis" publicada em fevereiro de 1995 (conf. lista de 'suframáveis', tem quase dez nomes, A CRÍTICA, 9/2/95, A12), todos os dez nomes que concorriam à sucessão de Manoel Rodrigues eram vinculados a políticos amazonenses: "Esses nomes são apadrinhados de políticos amazonenses, que estão estendendo seus tentáculos em busca de apoio em todas as regiões do país". O artigo também cita o condicionamento da viabilidade da administração, feita pelo governador Amazonino Mendes, à nomeação de um membro de seu grupo político. A disputa maior e mais significativa estava entre quem estava indicando, polarizada entre Amazonino Mendes e Artur Virgílio Neto.

Conforme verificamos anteriormente neste trabalho, a implantação da Zona Franca de Manaus foi assinalada por Márcio Souza como um golpe contra a burguesia local que acabou ficando com os postos subalternos. Este aspecto é tratado também por Motta, que destaca a característica geopolítica militar da criação da ZFM, processo no qual não houve a preocupação com a oligarquia amazonense. Aponta, no entanto, que isso não significou o fim da ampliação das redes patrimonialistas.

As disputas atuais que verificamos em relação ao cargo de superintendente demonstram uma profunda transformação, pois se não são técnicos ou políticos amazonenses que assumem a direção da SUFRAMA, parece haver, nas relações de força, uma cooptação dos superintendentes. "Os novos e poderosos interesses metamorfoseiam seus aliados, velhos 'botos-tucuxis' [...], novos Cabrais, tanto uma 
velha oligarquia, quanto novos funcionários do autoritarismo se arranjam com os novos poderes..." (OLIVEIRA, 1994, p. 92). Um golpe dentro do golpe, a aparente passividade amazonense novamente impõem-se e, na sua linguagem, nem tanto estratégica do ponto de vista da ação racional burocrática, "vulgar" consegue imporse pela tradição e pelo carisma.

Este é um aspecto patente que pudemos verificar na leitura das atas, quando Amazonino Mendes sobressai-se como líder, reconhecida sua "aura" no interior do CAS, quando os governadores dos outros Estados não se opõem diretamente à ZFM, mas o fazem à SUFRAMA, à burocracia do governo federal.

Por outro lado, quanto às relações governador/superintendente, se no interior das reuniões do CAS verificamos um ritual de cordialidade, onde as disputas entre suas respectivas propostas são representadas como em direção ao interesse comum, na imprensa existe um enfrentamento mais aberto onde a pessoa do governador faz constantes ataques aos "inimigos" da ZFM. Conforme assinala Francisco de Oliveira: "Na retaliação pessoal opera-se a ilusão de um confronto de sujeitos; na realidade, a retaliação individual mascara a onipotência dos processos destrutivos coletivos, que permanece quase intocada. E a favor dos mais poderosos" (OLIVEIRA, 1994, p. 92). As próprias disputas entre Amazonas e São Paulo operam uma ilusão quanto aos reais interesses.

Um outro elemento importante apontado por Motta refere-se aos privilégios dos empresários, sua conclusão remete à combinação, na Zona Franca de Manaus, de um capitalismo de pária com o despotismo hidráulico. Há, por conseguinte, um caráter aventureiro nos investimentos, pois o atrativo da ZFM são os incentivos fiscais. Segundo o autor, a maioria das empresas que veio para a ZFM era marginais em relação ao capitalismo internacional. E há também uma burocracia privilegiada, marcada pelo significado da própria SUFRAMA, como um locus de poder burocrático.

O período ao qual se refere Motta, bem como o ponto de partida de sua análise, parece não ter permitido a percepção da vinculação da Zona Franca de Manaus com o capitalismo mais desenvolvido, fato que ganhou visibilidade com o processo de globalização econômica. Silva demonstra como a referência da nação produziu o fenômeno de refração nas análises dos militares, dos intelectuais. 
Centrando a análise sobre a SUFRAMA como órgão burocrático a partir da consulta das sete atas disponíveis, podemos verificar diversas divergências entre o objetivo para o qual foi constituído seu Regimento Interno e suas ações concretas.

A SUFRAMA tem seu funcionamento orientado a partir do Planejamento Estratégico, realizado de dois em dois anos, a partir do qual são elaboradas as diretrizes gerais, além disso é definido um Plano de Ação anual. Sua direção está a cargo do Conselho de Administração da SUFRAMA - CAS, que deveria reunir-se uma vez ao mês conforme seu Regimento Interno, e de dois em dois meses conforme orientações da direção atual; no entanto, conforme as atas consultadas, de dezembro de 1994 a outubro de 1997, foram realizadas sete reuniões ordinárias. Isto significa que a atribuição principal da autarquia, na prática à distribuição de cotas de importação, permaneceu centralizada a maior parte do tempo nas decisões do superintendente do órgão. Além do que não existem critérios definidos em relação à distribuição das cotas, o próprio conteúdo das reuniões deixou clara a prioridade aos projetos que tivessem maiores investimentos e, teoricamente, maior geração de empregos. Nenhum indício de prioridade à utilização de matéria-prima regional. Quanto a isso parece não haver muito interesse dos próprios governadoresconselheiros. Quando questionam a SUFRAMA, nas reuniões, é muito mais por pleitearem os benefícios fiscais da ZFM e a aplicação dos recursos a fundo perdido da SUFRAMA nos Estados do que discutir sobre a utilização da matéria-prima regional.

A própria geração real de emprego não é fiscalizada. A reivindicação do representante da classe trabalhadora, Wilson Paixão, na 175. ${ }^{a}$ Reunião Ordinária realizada em março de 1997, torna patente este fato: "Ano passado, durante as três reuniões realizadas do Conselho, nós aprovamos mais de 70 projetos tanto de ampliação quanto de instalação, gerando em torno de aproximadamente 12 a 13 mil empregos. Até hoje estes empregos não apareceram. Onde estão esses empregos?"

Outra questão que apareceu com as leituras das atas, e que está presente em todos os debates, foi a seguinte: a SUFRAMA é uma agência de desenvolvimento? Neste sentido, a 174. ${ }^{\text {a }}$ (de 6/12/96) Reunião foi esclarecedora, pois demonstra a dramática desigualdade de tratamento dos diversos Estados da Amazônia Ocidental,

174 Somanlu, ano 4, n. 1, jan./jun. 2004 
quando nas palavras de Osmir Lima, deputado estadual do Acre, a SUDAM beneficia somente o Pará, e a SUFRAMA restringe seus benefícios ao Amazonas. Para termos uma idéia deste fato é interessante observarmos alguns dados sobre aplicação de recursos em 1997. Os $\mathrm{R} \$ 77,8$ milhões dos convênios da SUFRAMA com os governos estaduais foram assim distribuídos: 45,2 milhões para o Amazonas, 18,4 milhões para Rondônia, 11,1 milhões para Roraima, 1,1 milhão para o Amapá e 687,8 mil para o Acre (A Crítica, 11/1/98, E7).

Este montante corresponde a apenas $40 \%$ dos recursos da SUFRAMA a título de fundo perdido, pois conforme a decisão do CAS, na 176. ${ }^{a}$ Reunião Ordinária de $1 . \% / 8 / 97,60 \%$ deveria ser rateado igualmente entre os Estados, ou seja, cerca de $\mathrm{R} \$ 116,7$ milhões, cabendo cerca de $\mathrm{R} \$ 23,34$ milhões para cada Estado. Os recursos destinados ao Estado do Amazonas podem ser acrescidos do ICMS arrecadado. Segundo os Indicadores Industriais da SUFRAMA a arrecadação foi de, aproximadamente, em 1995, US\$203.533.549; em 1996, US\$247.199.639 e, em 1997, até o mês de junho, US\$100.957.492.

Ressalte-se que a distribuição dos recursos à qual nos referimos anteriormente foi realizada a partir de critérios definidos pelo CAS. Antes de agosto de 1997, portanto, esta decisão dependia exclusivamente do superintendente.

A SUFRAMA tanto não cumpriu sua função que os governadores freqüentemente criticam as reuniões do CAS, que se restringem à aprovação de projetos para a Zona Franca de Manaus e propõem a transformação da SUFRAMA, se não a sua substituição, por uma agência de desenvolvimento da Amazônia Ocidental. Isto, porém, não ocorreu somente neste órgão, pois o BASA e a SUDAM também estão sendo postos em questionamento e buscando, tal como a SUFRAMA, resgatar sua credibilidade a partir de uma reestruturação desses órgãos por meio de maior contato com os Estados, definição de critérios para aplicação de recursos, bem como da imagem dos seus dirigentes enquanto técnicos. O discurso do Sr. Artur Tourinho - superintendente da SUDAM, representa esta tendência: "Não tenho nenhuma vinculação a nenhum partido político, eu faço política ocupando com muita honestidade, com muita seriedade, muita transparência e muita vontade de trabalhar..." e "reunião de trabalho é discurso técnico, é discutir as necessidades do Estado” (174. ${ }^{a}$ Reunião Ordinária, anexo VIII). 
O debate sobre as agências de desenvolvimento mostra um outro lado, ao qual já nos referimos anteriormente. Há um despreparo, uma ausência de assessoria dos órgãos (com conivente beneficiamento de alguns) ou um desinteresse por recursos para projetos agropecuários e que utilizem recursos regionais. O discurso de Flora Valladares, do BASA, demonstra que nem com critérios para distribuição de recursos é garantida a participação dos Estados menores. Em 1996, por exemplo, apesar de os recursos estarem disponíveis, não houve apresentação de projetos.

As reivindicações de atenção, por parte da SUFRAMA, para com os Estados de Roraima, Rondônia e Acre aparecem em todas as reuniões, chegando a posicionamentos extremos, como do governador do Estado de Rondônia, Waldir Raupp, quando decide pedir vistas de todos os processos da 175. ${ }^{a}$ Reunião Ordinária em função da divergência quanto aos critérios de distribuição dos recursos financeiros da SUFRAMA entre os Estados.

A gestão atual da SUFRAMA representa-se como reestruturadora do órgão, uma gestão técnica, contrapondondo-se a gestões políticas que a antecederam, propõe-se a resgatar a imagem do órgão. "A SUFRAMA foi um feudo da Administração Estadual até a gestão passada", segundo Aristides Oliveira Júnior, integrante da Coordenação de Estudos Econômicos e Empresariais - CEE, referindo-se à recomposição do CAS e atualização do Plano Estratégico realizados em 1996.

A crise e suas possibilidades

Desde sua implantação, a ZFM passou por diversas fases. No final dos anos 60 e na década de 70 , foi favorecida em função da exclusividade em relação aos produtos importados, detinha o monopólio desses produtos no Brasil. Um quadro diferente delineia-se no final dos anos 70 e 80, com a liberação das viagens ao exterior e quando, com as pressões da indústria nacional, começam as ameaças de contingenciamento, o que não é de todo inesperado em função do próprio modelo pensado enquanto substituição de importações. O contingenciamento num momento de crise econômica, se por um lado possibilita o surgimento de médias e pequenas

176 Somanlu, ano 4, n. 1, jan./jun. 2004 
empresas de componentes, por outro torna esses produtos mais caros. Também nessa década começam as exigências de crescentes índices de nacionalização dos produtos. Com a abertura econômica em 90 , as empresas perdem as condições de competitividade em função dos custos, há a necessidade de adequação à Nova Política Industrial e de Comércio Exterior - PICE. O PICE foi implantado com o fim de estimular a produtividade e a qualidade e proporcionar maior competitividade à indústria nacional em níveis interno e externo.

No ano de 1997 ocorreram três grandes crises: as pressões para a saída do superintendente Mauro Costa, o pacote do governo federal que cortou em 25\% os incentivos fiscais, além da comissão de investigação da maquiagem de produtos na ZFM. Com a pressão política sobre o pacote fiscal, o governo federal retrocedeu. Um dos fortes argumentos utilizados foram acerca dos tributos federais recolhidos no Norte. Segundo a Delegacia da Receita Federal, de janeiro a novembro de 1997, do montante arrecadado no Norte, 54,97\% foram recolhidos no Estado do Amazonas, os 45,03\% restantes nos outros Estados da região (A CRÍTICA, 28/12/ 97, E3).

Podemos dizer que desde a sua criação, a ZFM esteve em crise. No seu projeto, os desencantamentos; na sua direção, os embates entre o governo estadual e o poder dos superintendentes; nos seus desdobramentos, a frustração do distrito agropecuário sem resultados concretos; do distrito industrial sem valorizar a matériaprima regional e conseguir dinamizar a economia do Estado e da Amazônia Ocidental; e no momento atual quando se consegue visualizar a globalização econômica, na qual, conforme aponta Silva, a Zona Franca de Manaus pode ser considerada, desde o início, como um “espaço global”, há a possibilidade de afugentar esta economia global (SILVA, 1997, p. 45).

A também crise constante entre os rumos do capitalismo e os interesses nacionais, embora possamos analisá-la como uma contradição aparente, bem serve aos propósitos político-partidários e ainda apresenta-se como um argumento eficiente na guerra fiscal.

A grande questão de fundo, contudo, contra a qual todos se embatem é a seguinte: Por que a ZFM não conseguiu tornar-se uma zona franca do tipo superior, 
o qual “...goza de total autonomia até o nível de renúncia da determinação da sua política econômica nacional?” (NICÁCIO apud SILVA, 1997, p. 42). Ou por que não conseguiu desencadear um processo de desenvolvimento regional vinculado a um projeto nacional?

A resposta a ambas não é una, a não ser que possamos afirmar que não ocorreu nem uma coisa nem outra em função das contradições sociais, de forma genérica, que resultou num desfecho inesperado, embora nem de todo imprevisível conforme destaca Silva acerca da análise de Freitas Pinto. Temos, então, mais uma "tragédia", cuja causa pode ter sido "o protecionismo sob a forma de nacionalismo", ou a ausência de um projeto de desenvolvimento nacional, ou ambos. Seus avanços e recuos nas relações de força concretas das quais temos pouco mais que os desfechos ou as projeções racionais das ações.

Os rumos da Zona Franca de Manaus estão entre uma reestruturação do modelo, o que é lugar-comum, e a possível perda dos incentivos fiscais em 2013. Quanto à reestruturação, o próprio governo federal está operando adequações com maior controle sobre as empresas, da qual faz parte a adoção de novos critérios para a aprovação dos projetos (LEI n. ${ }^{\circ}$ 9.532); a reestruturação da SUFRAMA é defendida pelo superintendente da autarquia, cujo representante aponta contradições entre a proposta do próprio governo federal e a posterior Medida Provisória n. ${ }^{\circ}$ 1.602 e a Lei n. ${ }^{\circ}$ 9.532. Há também a controvertida proposta do senador Jefferson Péres, cujo objetivo consiste em "transformar a Zona Franca num efetivo instrumento de desenvolvimento econômico"; segundo ele, "trinta anos de Zona Franca já provaram, à exaustão, que o modelo é eficiente na atração de investimentos e na geração de renda, mas concentrador nos sentidos espacial e social, em benefícios apenas de Manaus e de alguns extratos da população. Não se irradia para o interior nem distribui renda" (A CRÍTICA, 28/12/97), sua intenção, segundo ele, é mobilizar a sociedade para elaborar uma proposta comum sobre a Zona Franca de Manaus.

Orientações menos extremadas aparecem na formulação do economista Rodemarck Castelo Branco, um dos mais importantes interlocutores sobre a ZFM no Estado, para quem "uma das saídas é verticalizar o parque industrial da ZFM, trazendo empresas de componentes para gerar escala de produção e criar o fator fundamental de competitividade, principalmente do setor eletroeletrônico, que é a

178 Somanlu, ano 4, n. 1, jan./jun. 2004 
interação dos fornecedores e empresas de bens finais", e concomitantemente criar condições para acumulação regional do capital, que propicie o surgimento de pequenos e médios negócios, com a valorização das potencialidades regionais.

O quadro que se delineia, revela um tardio reconhecimento dos problemas presentes no próprio modelo, bem como dos vícios presentes nas agências de desenvolvimento que ensaiamos questionar se havia uma relação de continuidade. Na década de 70, já havia formulações que apontavam diversos problemas e suas possíveis superações como as de Djalma Batista, que se preocupava com a instalação de fábricas de montagem de aparelhos eletrônicos e para assegurar o desenvolvimento do Estado, sugeria, dentre outras medidas: "fiscalização dos lucros do comércio e da indústria, e legislação objetivando reter no Amazonas pelo menos uma parte dos mesmos, em aplicações concretas"; “estímulo ao aproveitamento de matérias-primas regionais no processo de industrialização (evitando que as fábricas se esvaziem quando cessarem os favores fiscais): madeiras, incluindo compensados; celulose e papel[...]" (BATISTA, 1976, p. 270). Foram, no entanto, necessários mais de vinte anos para que o próprio poder público estadual reconhecesse as distorções. Em artigo recente o governador Amazonino Mendes declara: “[...]desperdiçamos quase trinta anos de receita pública originária deste verão sem procurar direcionar investimentos que nos dessem o mínimo de resguardo para a instabilidade que já era flagrante. A Constituição de 88 nos acordou, dando-nos, com a sobrevida de mais 25 anos, uma nova chance. Será imperdoável perante a História não aproveitarmos esta segunda oportunidade, embora em meio a todos esses sobressaltos". Ao contrário do que se poderia esperar, este reconhecimento não se pauta por uma abertura para pensar séria e democraticamente a reestruturação do modelo da ZFM, mas para justificar os investimentos no $3{ }^{\circ}$ Ciclo: “O $3 .{ }^{\circ}$ Ciclo não é propriedade de ninguém, é doutrina de redenção e de libertação de todo um povo” (A CRÍTICA, 23/11/97).

Apesar disso a "mística do desenvolvimento regional", que parecia cada vez mais distante, recrudesce, num certo sentido, tanto regional como nacionalmente. Mas os próprios critérios para concessão dos incentivos fiscais na "práxis", conforme depoimento de Aristides da Rocha F. Júnior, até o momento privilegiam os maiores investimentos.

Somanlu, ano 4, n. 1, jan./jun. $2004 \quad 179$ 
Quanto aos trabalhadores, se antes havia o questionamento do modelo, a partir de 1988, os sindicatos operários e suas lideranças políticas passaram a defender seus empregos (SILVA, 1977, p. 44). A própria iniciativa de criar um movimento pró-ZFM (A CRÍTICA, 6/2/98), de iniciativa da Força Sindical e do Sindicato dos Metalúrgicos, demonstra esta posição, a qual não pode ser avaliada como "desindexada de ideologias", como quer fazer parecer José Roberto Tadros, presidente da Federação do Comércio do Estado do Amazonas - FACEAM (A CRÍTICA, 21/ 1/98). Impõe-se aqui a "hiper-realidade" como justificação ideológica sobre a qual Boaventura de Souza Santos nos chama atenção. O grande desafio hoje não é reconhecermos que a realidade tal como está era inevitável, mas surpreendermonos com a realidade que se teoriza a si mesma.

Os impactos da globalização e da reforma do Estado brasileiro nos rumos da Zona Franca de Manaus

As fases pelas quais passou a Zona Franca de Manaus, seus percalços, aos quais nos referimos anteriormente, podem ser melhor compreendidas quando relacionadas à estrutura do Estado brasileiro. A análise de Albuquerque (1995) sobre a história do Estado brasileiro, particularmente nos períodos correspondentes a "o Estado como superinstituição", de 1930 a 1980, e a crise de 1980 a 1995, fornecemnos elementos que explicitam as próprias contradições nas decisões do governo federal quanto a ZFM.

O Estado como superinstituição consolidou-se concomitantemente com o nacional-desenvolvimentismo. É ele que viabiliza a infra-estrutura e o desenvolvimento industrial a partir do centralismo. De 1930 a 1970, seja através da infra-estrutura, seja diretamente como empresário, o Estado, segundo Albuquerque, chega "[...] a responsabilizar-se por mais da metade da formação bruta de capital fixo do país. E gradualmente se transformou em gigantesca e centralizada superinstituição que tudo pretendia prever e prevenir e quase tudo procurava prover e programar" (1995, p. 139). $O$ auge desta condição foi alcançado na década de 70 , em função do controle do Estado sobre o Congresso Nacional e da sua organização administrativa em grandes sistemas. O Poder Executivo da União torna-se "um espaço por excelência de afirmação da tecnoburocracia".

180 Somanlu, ano 4, n. 1, jan./jun. 2004 
Apesar de modernizador, acentua o autor que o Estado preserva "práticas anacrônicas" que se ampliam na década de 80 e início de 90 , com a crise econômica e a abertura política. São remodelados: o velho patrimonialismo, o cartorialismo clientelista e o corporativismo. $O$ primeiro inicialmente representava a ampliação do poder tutelar sobre a sociedade e, posteriormente, significou o emprego dos poderes públicos para obter benefícios pessoais. O segundo "de início centrado nos amplos poderes de conceder, voluntariamente, a pessoas e entidades privadas, financiamentos, incentivos fiscais e outros privilégios, mais tarde, envolvendo o uso desses mesmos poderes para obter, muitas vezes em detrimento do interesse público, vantagens individuais" (ALBUQUERQUE, 1995, p. 140). O terceiro inicialmente fortalecendo os poderes do estamento tecnoburocrático, mais tarde, ampliando sua influência com adesão da nova força emergente: a dos políticos, para assegurar ou ampliar direitos e prerrogativas.

A desagregação do Estado como superinstituição ocorre na década de 80, a partir daí se delineia a exigência de sua reestruturação. Três crises foram fundamentais no seu desencadeamento e ainda se fazem presentes: a crise de legitimidade do Estado autoritário, a crise financeira e a crise existencial. A crise de legitimidade do Estado autoritário tem lugar com a autonomia e significado adquiridos pela luta para a democratização, cuja condução foi minada pela recessão de 1981-83. A crise financeira "resulta da ampliação do fosso entre as receitas próprias da União e suas necessidades de financiamento" (ALBUQUERQUE, 1995, p. 141). A crise denominada pelo autor de existencial refere-se aos "alicerces institucionais" e a "identidade do próprio ente estatal", "sua razão de ser e consciência de si mesmo; sua capacidade decisória e funcionalidade; sua percepção da sociedade; e a imagem que projeta perante ela" (ALBUQUERQUE, 1995, p. 142).

A ausência de um projeto desde a década de 80 demonstra uma perda na autoconsciência do Estado, um processo de desestruturação que gerou uma "insciência institucional”. A própria capacidade decisória do governo "esgarçou-se” na transição democrática. A tentativa da Nova República de reduzir o gigantismo do Estado concorreu para sua desestruturação em função de um “[...]transformismo organizacional destrutivo e desestabilizador[...]”, nas palavras de Albuquerque (1995, p. 143). 
Neste contexto é instalada a constituinte, cujo resultado corresponde a ausência de visão das novas tendências: a globalização da economia, a liberalização dos fluxos comerciais e de capital, a formação de grandes blocos regionais e suas repercussões sobre o papel do Estado na economia.

O governo Collor incorpora a vertente liberalizadora, porém contraditoriamente interfere no mercado e na vida financeira privada. Quanto ao Estado, a reforma administrativa aprofunda sua desestruturação. E como agravante "leva a extremos a fruição patrimonialista e cartorial do Estado e o uso organizado dos poderes públicos como forma de obter benefícios pessoais da iniciativa privada", processo que culminou no impeachment (ALBUQUERQUE, 1995, p. 144).

O governo Itamar Franco consegue restabelecer a respeitabilidade pública e o atual se propôs a reconstruir, em bases modernas e mais funcionais, o Estado brasileiro.

Conforme podemos verificar, a crise da ZFM corresponde a também crise do Estado brasileiro, entre uma forma de acumulação primitiva de capital, a indústria nacional e a adequação às exigências da globalização econômica.

A reestruturação da SUFRAMA relaciona-se diretamente ao restabelecimento da credibilidade das instituições, reflexo da imagem projetada pelo atual governo, o que no entanto está em xeque dados os escândalos observados nas instituições públicas, envolvendo os três poderes: Executivo, Legislativo e Judiciário desde o ano passado.

O processo de globalização tem um efeito profundo sobre a ZFM, pois não corresponde a uma mudança setorial do capitalismo, que ocorre no seu interior, mas a profundas transformações em toda a sociedade. A utilização indiscriminada da globalização tem gerado uma considerável dificuldade de compreender o seu alcance, o complexo de mudanças que a representam.

A análise de Ohmae (1996) demonstra a importância dos fluxos dos investimentos, da indústria, da informação e dos consumidores individuais que passam a ter "uma orientação mais global". Isto significa dizer que não só as indústrias tenham sofrido mudanças, mas que essas mudanças relacionam-se com as exigências individuais, com um novo sentido na configuração da territorialidade,

182 Somanlu, ano 4, n. 1, jan./jun. 2004 
com a velocidade das informações, com a perda de poder dos Estados nacionais. Os incentivos fiscais deixaram de ser o grande atrativo e dão lugar a "recursos atraentes", que guardam cada vez menor dependência de concessão dos Estados nacionais. Neste sentido a tendência dos Estados nacionais não é de se orientarem pela centralização do planejamento, isto porque deixaram de ser os "protagonistas" das aspirações econômicas e sociais.

O reflexo nas indústrias que não reduziram os custos e investiram na qualidade total é imediato, não conseguem competir perante as novas exigências, pois os consumidores buscam os produtos mais baratos, independente de onde foram produzidos. As ambíguas decisões do governo federal, ora mantendo os incentivos, ora retirando-os, resulta da adequação do modelo às novas exigências, combinadas senão a um projeto, mas a uma orientação de desenvolver e proteger uma indústria nacional embora tardiamente.

A ZFM se por um lado antecipa a presença do capital globalizado no Brasil (na sua primeira versão), por outro se consolidou de tal forma na dependência dos incentivos fiscais e nas articulações políticas de interesses privados que sua transição manifesta-se como o fim. O maior problema da Zona Franca de Manaus parece localizar-se não apenas no seu modelo, pois produziu recursos que poderiam ter sido aplicados na dinamização da economia regional, mas resulta também das prioridades de investimento, definidas no âmbito das estruturas e do poder político.

\section{Referências}

ALBUQUERQUE, Roberto Cavalcanti de. Reconstrução e Reforma do Estado. In: VELOSO, João Paulo dos Reis; ALBUQUERQUE, Roberto Cavalcanti de (Coord.). Governabilidade \& reformas. Rio de Janeiro: José Olympio, 1995. p. 129-198.

BATISTA, Djalma. O complexo da Amazônia: análise do processo de desenvolvimento. Rio de Janeiro: Coleção Temas Brasileiros, 1976.

BOURDIEU, Pierre. La Construcción del Objeto. In: El ofício de sociólogo. Pressupuestos epistemológicos. Espanha: Siglo Veintiuno, 1981. p. 51-81. 
CANCLINI, Nestor Garcia. Do primitivo ao popular: teorias sobre a desigualdade entre as culturas. In: As culturas populares no capitalismo. São Paulo: Brasiliense, 1983.

COSTA, Heloísa Lara Campos da et al. Crescimento econômico e pobreza: efeitos das políticas públicas. In: Politicas públicas, desigualdades sociais e crianças no Amazonas. Belém: UNAMAZ/FUA/UFPA, 1993. (Série Pobreza e Meio Ambiente na Amazônia, 5.)

CHAUI, Marilena. Cultura do Povo e Autoritarismo das Elites. In: Cultura e democracia: o discurso competente e outras falas. 3. edição. São Paulo: Moderna. (Coleção Contemporânea), 1982.p. 39 - 60.

DIÁRIO OFICIAL DA UNIÃO. 19 de junho de 1957. Lei n. ${ }^{\circ}$ 3.173, de 6 de junho de 1957.

FREITAS PINTO, Ernesto Renan de. Como se produzem as Zonas Francas. Revista Seminário e Debates, Belém, p. 19-38, 1987.

IANNI, Octavio. A sociedade global. Rio de Janeiro: Civilização Brasileira, 1992.

JORNAL A CRÍTICA. A reestruturação da ZFM. Manaus, 15 de fev. de 1997, E4/ 5.

ZFM, o segundo ciclo faz três décadas. Debate. Manaus, 28 de fev. de 1997, p. 3.

Debate sobre o desemprego mostra soluções distantes. Manaus, 27 de jul. de 1997, E6/7.

MP corta incentivos da Zona Franca. Manaus, 16 de nov. de 1997, A5 e

E8.

ZFM - o futuro imediato: debate propõe reformulação da Zona Franca de Manaus. Manaus, 23 de nov. de 1997, E6/7.

Indústria é o setor que mais emprega no país. Manaus, 18 de dez. de 1997, C9.

Péres quer reaplicação da receita da ZFM. Manaus, 21 de dez. de1997, E10.

Manaus, 11 de jan. de 1998, E3.

184 Somanlu, ano 4, n. 1, jan./jun. 2004 
. Desemprego faz mudar as relações de trabalho. Manaus, 21 de jan. de 1998. Manaus, 6 de fev. de 1998. Economia. . Lista de 'suframáveis' tem quase dez nomes. Manaus, 9 de fev. de 1995, A12.

LOUREIRO, Jorge Alberto S. Zona Franca de Manaus - sonho de tigre na realidade de gato-do-mato. Manaus. A Crítica, 11 de jan. de 1998.

MANTEGA, Guido. A economia politica brasileira. 5. ed. Petrópolis: Vozes, 1990.

MARINHO, Euclésia Pereira. A política de incentivos fiscais e a evasão de rendas na Zona Franca de Manaus: reflexos. Universidade do Amazonas, Faculdade de Estudos Sociais. Monografia.

MASCARENHAS, Ednéia. A ilusão do fausto: Manaus 1890 - 1920. Dissertação (Mestrado). PUC, São Paulo, 1988.

MENDES, Amazonino. Aprendendo com a crise. A Crítica, Manaus, 23 de nov. de 1997, A5.

MOTTA, Roberto. La Zone Franche de Manaus et le mode paria de la production. Cabiers du Brésil contemporain, n. 11, p. 27-48.

OHMAE, Kenichi. O fim do Estado-Nação: a ascensão das economias regionais. Rio de Janeiro: Editora Campus, 1996.

OLIVEIRA, Francisco. Elegia para uma re(li)gião: Sudene, Nordeste, Planejamento e conflito de classes. 5. ed. São Paulo: Paz e Terra, 1987. (Série Estudos sobre o Nordeste, 1.)

A reconquista da Amazônia. In: D’INCAO, Maria Ângela; SILVEIRA, Isolda Maciel da. A Amazônia e a crise da modernizaçãa. Belém: Museu Paraense Emilio Goeldi, 1994. p. 85-95. (Coleção Eduardo Galvão)

PÉRES, Jefferson. ZFM: negociação ou morte. A Crítica, Manaus, 23 de nov. de 1997, A4.

. Vamos virar o jogo. A Crítica, Manaus, 21 de dez. de 1997, A4. 
RIBEIRO, Marlene. De seringueiro a agricultor/pescador a operário metalúrgico: um estudo sobre o processo de expropriação/proletarização/ organização dos trabalhadores amazonenses. Dissertação (Mestrado). Minas Gerais: Universidade Federal de Minas Gerais, 1987. ROLDÃO, Rosineide de Melo. A nova política de incentivos para a ZFM: impactos e perspectivas. Manaus: Universidade Federal do Amazonas, Faculdade de Estudos Sociais, 1992. Monografia.

SALAZAR, João Pinheiro. O abrigo dos deserdados: estudo sobre a remocão dos moradores da cidade flutuante e os reflexos da Zona Franca na habitação da população de baixa renda em Manaus. Dissertação (Mestrado). São Paulo, Universidade de São Paulo, 1985.

SANDRONI, Paulo. Desenvolvimentismo. In: Novo dicionário de economia. Ed. Bete Seller, 1994.

SOUZA, Márcio. A expressão amazonense: do colonialismo ao neocolonialismo. São Paulo: Ed. Alfa-ômega, 1978.

SILVA, Marilene Corrêa da. Metamorfoses da Amazônia. Tese (Doutorado). Universidade Estadual de Campinas, Departamento de Ciências Sociais, Instituto de Filosofia e Ciências Humanas, 1997.

Região e Nação. In: O paiz do Amazonas. Manaus: Editora da Universidade Federal do Amazonas, 1996. p. 211 a 217.

SIMONSEN, Mário Henrique; CAMPOS, Roberto de Oliveira. A Experiência Brasileira de Planejamento. In: A nova economia brasileira. Rio de Janeiro: J. Olympio, 1974. p. 47-78.

WEBER, Max. Os tipos de dominação. In: . Economia e sociedade. fundamentos da sociologia compreensiva. Brasília: Editora da Universidade de Brasília, 1991. p. 139-198.

ZONA FRANCA de Manaus: história e objetivos. (1996). Manaus: SUFRAMA Coordenadoria de Comunicação Social.

186 Somanlu, ano 4, n. 1, jan./jun. 2004 